\title{
Surgical Complications of Live Related Renal Transplantation
}

\author{
Hafiz Shahzad Ashraf, ${ }^{1}$ Muhammad Seerwan, ${ }^{2}$ M. Nasir Ibrahim, ${ }^{3}$ Nadir Hussain, ${ }^{4}$ Rana Atta-ur-Rehman ${ }^{5}$
}

\begin{abstract}
Introduction: Renal transplantation is the treatment of choice for patients with end stage renal disease. It offers marked improvement in the quality of life of patients who undergo this form of treatment. Surgical complications are important in the sense that they can lead to loss of allograft and in severe cases loss of patient life. The aim of this study is to determine the frequency of surgical complications after renal transplantation in our population.
\end{abstract}

Materials and Methods: We retrospectively reviewed the surgical complications in 350 patients who had live related renal transplantation performed at Postgraduate Medical Institute, Shaikh Zayed hospital Lahore from January 2007 to December 2013.

Results: Among 57 (16.1\%) surgical complications

\section{Conflict of Interest: No}

Funding Source: No

Ashraf H.S. ${ }^{1}$

Professor and Head of Kidney Transplant Unit

Shaikh Zayed Hospital, Lahore

Seerwan M. ${ }^{2}$

Registrar Dept of Urology, Shaikh Zayed Hospital, Lahore

Ibrahim M.N. ${ }^{3}$

Senior Registrar, Department of Kidney Transplant Unit

Shaikh Zayed Hospital, Lahore

Hussain N.4

Assistant Professor, Department of Kidney Transplant Unit

Shaikh Zayed Hospital, Lahore

Rehman R.A.U. ${ }^{5}$

Registrar, Department of Urology

Shaikh Zayed Hospital, Lahore
$18(5.1 \%)$ had urological complications. Urinary fistulae, ureteral stenosis, ureteral stricture and hematuria occurred in 9 (2.5\%), 4 (1.14\%), 4 (1.14\%) and 1 $(0.28 \%)$ patients respectively. Vascular complications occurred in $5(1.42 \%)$ patients in total. $2(0.57 \%)$ patients had renal artery thrombosis and $1(0.28 \%)$ patient had renal vein thrombosis. $2(0.57 \%)$ patients had thrombosis of external iliac artery. Lymphocele occurred in 17 (4.8\%) of patients and wound infection developed in $19(5.4 \%)$ patients.

Conclusion: Surgical complications after kidney transplantation may be reduced or minimized if basic surgical principles of transplantation are followed. We conclude that kidney transplantation is a safe procedure with fewer surgical complications. The most important thing is the early diagnosis and prompt treatment of the complications in order to save the graft and the patient.

Keywords: Transplantation, Complications, Live related.

\section{Introduction}

The history of renal transplantation starts in the beginning of $20^{\text {th }}$ century. Its success depends upon the combination of the fields of surgery, medicine, immunology, and government. ${ }^{1}$ Carrel was the first person who established the modern technique of vascular anastomosis at the beginning of the 20th century. $\mathrm{He}$ was given the Nobel Prize in 1912 for his effort in the field of organ grafting. ${ }^{2}$

The first renal transplant in human beings was performed by Voronoy in the Ukraine in $1933 .^{3}$ A 26year-old woman was the recipient who had renal failure due to suicidal attempt by mercuric chloride. The kidney used for the transplant was taken from a 66year-old man, removed 6 hours after his death. This procedure was performed under local anesthesia. In

3 ANNALS VOL 22, ISSUE 1, JAN. - MAR. 2016 
this operation the renal vessels were anastomosed to the femoral vessels and a cutaneous ureterostomy was performed. After the procedure a small amount of blood - stained urine was produced. After the transplant the patient died 48 hours after transplantation. ${ }^{1}$

The first successful renal transplant in humans was performed in Boston in 1954. The patient survived for 1 year after the transplant. In this procedure the kidney was transplanted from one twin to the other, who had renal failure. ${ }^{4}$

Renal transplantation is the treatment of choice for patients with end stage renal disease..$^{5,6}$

It offers marked improvement in the quality of life of patients who undergo this form of treatment. Physical and psychosocial well-being scores, among patients who have undergone renal transplantation, reach levels comparable to those found in the general population. $^{7}$

Surgical complications in renal transplantation can be divided into vascular, urological and general surgical complications such as bleeding, wound infections and even lymphocele formation. ${ }^{8}$ These complications can lead to loss of allograft and in severe cases loss of patient's life.

The aim of this study is to determine the frequency of surgical complications after renal transplantation.

\section{Materials and Methods}

This is a retrospective review of the 350 patients who had live related renal transplantation performed at Postgraduate Medical Institute, Shaikh Zayed hospital Lahore from January 2007 to December 2013. The clinical records of all patients was retrieved retrospectively and analyzed. Preoperatively extensive work up for both donor and recipient was performed including HLA tissue typing and cross match and CT angiogram for evaluation of donor vessels. All patients were having first transplant. The majority of recipients had immunosuppression with triple regimen including Cyclosporin, mycofenyl mofeitil and corticosteroids. Revascularization was performed in a standardized manner. The graft renal vein was anastomosed in an end to side manner with external iliac vein. In majority of cases the graft renal artery was anastomosed by end to end technique to internal iliac artery, and in case of 2 arteries second artery was anastomosed to external iliac artery by end to side technique.

Ureteric reimplantation was done by utilizing modified single stich Lich Gregoire technique with or without DJ-stent. Drain was removed on $2^{\text {nd }}$ or $3^{\text {rd }}$ post op day according to drain output, Foley's catheter on $5^{\text {th }}$ and skin stitches on $14^{\text {th }}$ post op day. Patients were discharged on $6^{\text {th }}$ or $7^{\text {th }}$ post op day according to the condition of the patient with advice of regular follow up fortnightly for initial 3 months and monthly follow up for the $1^{\text {st }}$ year after transplantation.

\section{Results}

All patients had live related renal transplant. Among 350 patients $211(60.3 \%)$ were male and 139(39.7\%) were female. Male to female ratio was 1.51:1. The age of recipients ranged from 14 to 60 years with a mean age of 31.2 years.

Vascular complications occurred in 5 patients shown in the table given below, constituting an overall frequency of $(1.42 \%)$. There were $2(0.57 \%)$ patients who were diagnosed to have renal artery thrombosis and $1(0.28 \%)$ patients had renal vein thrombosis and $2(0.57 \%)$ patients developed thrombosis of external iliac artery. We encountered no patient with renal artery stenosis in our series.

Urological complications occurred in 18 patients (5.1\%) shown in graph below. Among these patients, 9

\begin{tabular}{|l|l|}
\hline \multicolumn{2}{|c|}{ Vascular complications } \\
\hline Renal artery thrombosis & 2 \\
\hline Renal vein thrombosis & 1 \\
\hline External iliac artery thrombosis & 2 \\
\hline
\end{tabular}

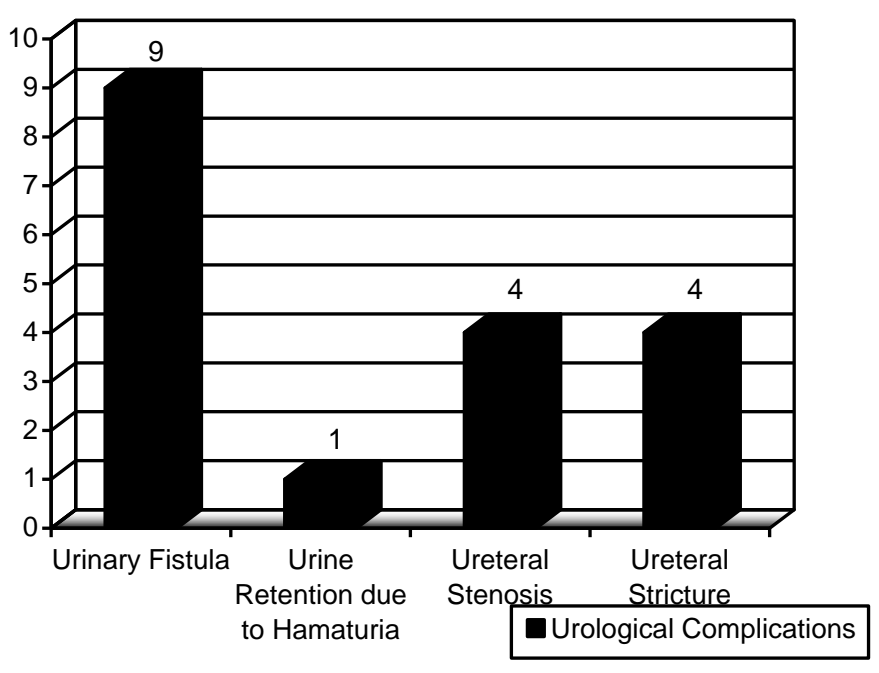

Fig. 1: Urological Complications. 
(2.5\%) had urine leak and were reexplored and ureteric reimplantation was done, $1(0.28 \%)$ patient had urine retention due to gross hematuria, 4 (1.14\%) patients had urine obstruction due to stenosis , and 4 (1.14\%) patients had ureteral stricture. We encountered UTI in $44(12.5 \%)$ patients and were managed by intravenous antibiotics according to culture and sensitivity.

In our series lymphocele was diagnosed in 17 (4.8\%) patients who were managed according to guidelines.

Wound infection occurred in $19(5.4 \%)$ patients.

\section{Discussion}

Renal transplantation has become safe now-a-days. In the early days of renal transplant, surgical complications were a major cause of graft loss. Between 1960 and 1980, the estimated incidence was around $20 \%$. With the improvement of surgical techniques, the frequency of these complications has dropped significantly. ${ }^{9,10}$ Recently, it has been shown in the literature that the incidence of surgical complications has dropped down to less than $5 \% .{ }^{11,12}$

Urological complications are the most common surgical complications after renal transplantation. Recent incidence of urological complications is between $2.5 \%$ to $12.5 \%{ }^{13}$, which is significantly lower than the $25 \%$ reported in the early days of renal transplantation. ${ }^{14}$

There are many factors responsible for urological complications but the two most important factors are the blood supply of distal ureter and the technique of reimplantation. ${ }^{15}$ The preservation of the blood supply of the distal ureter by careful preservation of the periureteric fat and the appropriate length of the ureter prevents the necrosis of distal ureter. The modified Lich Gregoire technique has replaced the technique of Lead better - Politano which had significant complications.

In our study the urological complications occurred in $18(5.1 \%)$ patients which is comparable to other series published. Shrestha BM et al 2006 reported overall incidence of urological complications $6.5 \%{ }^{15}$ In another study Chalise PR et al 2010 reported the incidence of urological complications $24 \%{ }^{16}$ Jacob A. Akoh and associates reported the incidence of urological complications $7.3 \%$. $^{17}$

The causes of different vascular complications are multifactorial. In some cases they are caused by technical errors, while in other cases recipient related fac- tors such as hypercoagulopathies and decreased cardiac output may be causative.

Renal artery thrombosis is an uncommon complication with reported incidence ranging from $0.5 \%$ to $3.5 \% .^{18}$ It is usually caused by technical reasons like twisting or kinking at the site of anastomosis and injury to intima resulting in dissection. Other causes like severe ATN, acute vascular rejection , poor cardiac output, thrombophilic states may cause renal artery thrombosis. ${ }^{19}$ Sudden cessation of urine output in early post operative days is usually the only mode of presentation. To make a timely diagnosis a very cautious approach is required in such cases. It is very important to have an immediate color Doppler ultrasound done whenever there is sudden decrease in urine output in early postoperative period. It is a surgical emergency and urgent exploration is required to restore the blood supply. But unluckly by the time it is diagnosed it is usually too late to salvage the graft and usually it ends in graft nephrectomy.

We encountered renal artery thrombosis in 2 $(0.57 \%)$ patients. Our results are comparable to other series published. Aneesh Srivastava et al in 2013 showed the incidence of renal artery thrombosis as $0.35 \%$ in his series. ${ }^{20}$ Mehdi Salehipour et al in 2009 showed the incidence of $0.6 \%{ }^{21}$

The reported incidence of renal vein thrombosis is 0.3 to $4.2 \% .{ }^{22}$ Causes are more or less same as that of renal artery thrombosis. It is usually more common with right sided grafts because of short length of renal vein which causes difficulty in anastomosis. Clinical presentation is usually with a sudden onset of oliguria and hematuria associated with pain or intense discomfort over graft area. Diagnosis is again confirmed by color Doppler which shows lack of flow in the renal vein. Emergency exploration is required to do venous thrombectomy and restore blood flow. In most of the cases it is usually not possible, so nephrectomy has to be done to save patient.

In our study, we only had $1(0.28 \%)$ patient who developed renal vein thrombosis. This is much less than the incidence reported in most of the series. The probable cause may be that we do only live related donors. The incidence of renal vein thrombosis is more in deceased donors as compared to living donors.

Transplant renal artery stenosis is the most common vascular complication seen after renal transplantation. The reported incidence of transplant renal artery stenosis is between $1 \%$ and $23 \% .^{23,24}$ We had not encountered any case of transplant renal artery stenosis in our series. 
Lymphocele is collection of lymph between the transplanted kidney and bladder. The average incidence of lymphocele in the literature ranges from 0.6 to $16 \% .^{25-27}$ The cause of lymphocele is inadequate ligation/inadvertent use of cautry during dissection of iliac vessels and/or during donor nephrectomy. The smaller lymphoceles are more common but they are usually asymptomatic. ${ }^{28}$ However, large sized lymphoceles present as a bulge at the site of graft. Very large lymphoceles can cause graft dysfunction by compressing on the ureter and causing hydronephrosis. ${ }^{29}$

The diagnosis is usually confirmed by ultrasound. $^{28}$ The treatment can be divided into expectant, puncture and drainage or surgery.

Small lymphoceles less than $140 \mathrm{ml}$ are asymptomatic and usually resolve spontaneously without any renal graft damage. Larger lymphoceles which manifests clinically can be treated by puncture and drainage under US or CT guidance. If recurrence occurs a sclerotherapy with povidone - iodine $5 \%$ ethanol or antibiotics can be performed. ${ }^{30,31}$

Very large lymphoceles greater than $500 \mathrm{ml}$ the laparoscopic lymphocele fenestration (Marsupialization) is the treatment of choice in many centers. In recurrent cases or when the condition is not favorable for laparoscopy the open surgical peritoneocystostomy with an oval window of at least $2.5 \times 5.0 \mathrm{~cm}$ in width should be performed. ${ }^{29}$

In our study $17(4.8 \%)$ patients had lymphoceles which is comparable to the most of the series published. $^{25-27}$

The reported incidence of post operative wound infection is 5\% after renal transplantation according to (Europian) Guidelines on renal transplantation 2012. Risk factors for wound infection include diabetes, haematoma, urinary fistula, obesity, rejection, over immunosuppression and old age. ${ }^{32,33}$ Mild infections can be treated by iv antibiotics while in cases of abscess formation it requires drainage.

In our study $19(5.4 \%)$ patients had mild wound infections managed by intravenous antibiotics and regular antiseptic dressings except one who has wound dehiscence who required aggressive wound management. Our wound infection rate is also comparable to most of the other series published. Faissal A.M. Shaheen et al in 2005 reported the incidence of wound infection as $2.9 \% .{ }^{34}$ Mohammed Mustafa Al-Habash et al 1999 reported the rate of wound infection as $17.5 \%$ in his series. ${ }^{35}$

\section{Conclusion}

Surgical complications after kidney transplantation may be reduced or minimized if basic surgical principles of transplantation are followed. We conclude that kidney transplantation is a safe procedure with fewer surgical complications. The most important thing is the early diagnosis and prompt treatment of the complications in order to save the graft and the patient.

\section{References}

1. Berry JM, Jordan ML, Conlin MJ. Renal transplantation. In: Wein AJ, Kavoussi LR, Novick AC et al, editors. Cambell - walsh urology. $10^{\text {th }}$ edition. Philadelphia: Saunders Elsevier, 2012: P.1227-28.

2. Hamilton D: Kidney transplantation, a history. In: Morris PJ, ed. Kidney Transplantation: Principles and Practice, 5th ed.. Philadelphia: WB Saunders; 2001: 18.

3. Hamilton DNH, Reid WA: Yu Yu Voronoy and the first human kidney allograft. Surg Gynecol Obstet. 1984; 159: 289.

4. Murray JE, Merrill JP, Harrison JH: Renal homotransplantation in identical twins. Surg Forum, 1955; 6: 432.

5. Suthanthiran M, Strom T. Renal Transplantation. N Engl J Med. 1994; 331 (6): 365-76.

6. Akbar SA, Jafri SZ, Amendola MA. Complications of renal transplantation. Radio Graphics, 2005; 25 (5): 1335-56.

7. Hilbrands LB, Hoitsma AJ, Koene RA. The effect of immunosuppressive drugs on quality of life after renal transplantation. Transplantation, 1995; 59: 1263-70.

8. Humar A, Key N, Ramcharan T, Payne WD, Sutherland DE, Matas AJ. Kidney retransplants after initial graft loss to vascular thrombosis. Clin Tranplant. 2001; 15 : 6-10.

9. Botto V, Cortese F, Baroni B, et al. Surgical complications in renal transplantation. Minerva Chir. 1993; 48 (21 - 22): 1341-1346.

10. Hernández D, Rufino M, Armas S, Gonzáles A, Gutiérrez $\mathrm{P}$, Barbero $\mathrm{P}$, Vivancos $\mathrm{S}$, Rodríguez $\mathrm{C}$, de Vera JR, Torres A. Retrospective analysis of surgical complications following cadaveric kidney transplantation in the modern transplant era. Nephrol Dial Transplant. 2006; 21: 2908-2915.

11. Dalgic A, Boyvat H, Karakayali G, et al: Urologic complications in 1523 renal transplantations: the Baskent University Experience. Transplant Proc. 2006; 38: 543.

12. Zargar MA, Shahrokh H, Fallah MMR, et al: Comparing Taguchi and anterior Lich - Gregoir ureterovesical reimplantation techniques for kidney transplantation. Transplant Proc. 2005; 37: 3077.

13. Emiroglu R, Karakayali H, Seumis S, et al: Urologic 
complications in 1275 consecutive renal transplantations. Transplant Proc. 2001; 33: 2016.

14. Starzl TE, Groth CG, Putman CW, et al: Urological complications in 216 human recipients of renal transplants. Ann Surg. 1970; 172: 1.

15. Shrestha BM, Darby CR, Moore. Ureteric complications following renal transplantation Kathmandu University Medical Journal. 2006; Vol. 4, No. 4, Issue 16: 409-414.

16 Chalise PR, Sharma UT, Gyawali PR, Shrestha GN, et al. Urological complications after Kidney transplantation. Kathmandu Univ Med J. 2010; 8 (31): 299-304.

17. Jacob A. Akoh, Abdu S. Opaluwa, Weller D. Urological Complications of Renal Transplantation: Reducing the Risk. Saudi J Kidney Dis Transpl. 2009; 20 (6): 1005-1009.

18. Rouvière $\mathrm{O}$, Berger $\mathrm{P}$, Béziat $\mathrm{C}$, et al. Acute thrombosis of renal artery: Graft salvage by means of intra-arterial fibrinolysis. Transplantation. 2002; 73: 403.

19. Irish A. Hypercoagulability in renal transplant recipients: Identifying patients at risk of renal allograft thrombosis and evaluating strategies for prevention. Am J Cardiovasc Drugs. 2004; 4: 139-49.

20. Srivastava A, Kumar J, Sharma S et al. Vascular complication in live related renal transplant: An experience of 1945 cases. Indian J Urol. 2013; 29 (1): 42-47.

21. Salehipour M, Salahi H, Jalaeian H, et al. Vascular Complications Following 1500 Consecutive Living and Cadaveric Donor Renal Transplantations: A Single Center Study. Saudi J Kidney Dis Transpl. 2009; 20 (4): 570-572.

22. Debleke D, Sacks GA, Sandler M. Diagnosis of allograft renal vein thrombosis. Clin Nucl Med. 1989; 14 (6): 415-20.

23. Bruno S, Remuzzi G, Ruggenenti P. Transplant renal artery stenosis. J Am Soc Nephrol. 2004; 15: 134-141.

24. Buturovic-ponikvar J. Renal transplant artery stenosis. Nephrol Dial Transplant. 2003; 18: v-74-7.
25. Adani, G. L., U. Baccarani, et al. Treatment of recurrent symptomatic lymphocele after kidney transplantation with intraperitoneal Tenckhoff catheter. Urology, 2007; 70 (4): 659-61.

26. Zargar - Shoshtari, M. A., M. Soleimani, et al. Symptomatic lymphocele after kidney transplantation: a singlecenter experience. Urol J. 2008; 5 (1): 34-6.

27. Iwan - Zietek, I., Z. Zietek, et al. Minimally invasive methods for the treatment of lymphocele after kidney transplantation." Transplant Proc. 2009; 41 (8): 3073-6.

28. Krol, R., A. Kolonko, et al. Did volume of lymphocele after kidney transplantation determine the choice of treatment modality? Transplant Proc. 2007; 39 (9): 27403.

29. Kahan BD, Ponticelli C. Principles and practice of renal transplantation. London. Martin Dunitz. 2000; 38 (3): 701-6.

30. Chandrasekaran, D., R. M. Meyyappan, et al. Instillation of povidone iodine to treat and prevent lymphocele after renal transplantation. BJU. 2003; Int 91 (3): 296.

31. Hamza, A., K. Fischer, et al. Diagnostics and therapy of lymphoceles after kidney transplantation. Transplant Proc. 2006; 38 (3): 701-6.

32. Dean PG, Lund WJ, Larson TS, et al. Wound-healing complications after kidney transplantation: a prospective, randomized comparison of sirolimus and tacrolimus. Transplantation, 2004 May; 77 (10): 1555-61.

33. Humar A, Ramcharan T, Denny R, et al. Are wound complications after a kidney transplant more common with modern immunosuppression? Transplantation, 2001 Dec; 72 (12): 1920-3.

34. Faissal A.M. Shaheen, Nawal Basri, et al. Experience of Renal Transplantation at the King Fahd Hospital, Jeddah, Saudi Arabia. Saudi J Kidney Dis Transplant. 2005; 16 (4): 562-572.

35. Mohammed Mustafa Al-Habash, Mohammed Bassam Al-Shaer, et al. Experience with Renal Transplantation at Al-Mouassat University Hospital, Damascus. Saudi J Kidney Dis Transplant. 1999; 10 (4): 526-530. 